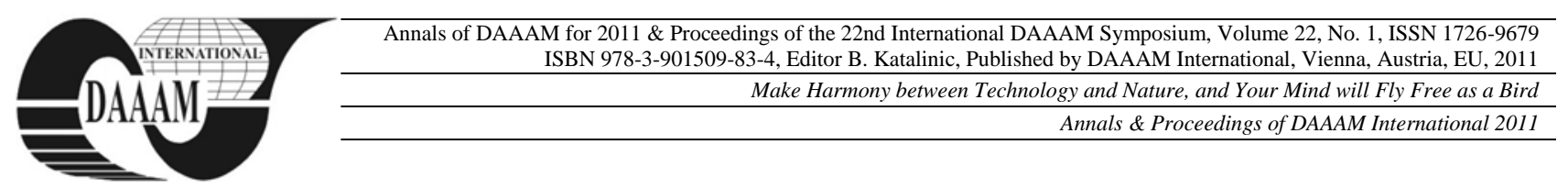

\title{
NECROMARKETING: WHEN UNEXPECTED AND UNWANTED IMPACT NOTORIETY
}

\author{
ROSCA, V[lad]
}

\begin{abstract}
The research tries to find out how death of people influences the brand of the organization they represent. The paper is based on a case study approach, the purpose being to find out if there is any correlation between tragedy and branding, and if it is, how does it manifest. A limitation of the paper is that, it does not offer any measurements which to indicate the influence on the brand capital.
\end{abstract}

Keywords: necromarketing, notoriety, death, brand capital

\section{INTRODUCTION}

The idea of the article came after realizing what an impact Steve Jobs' death had in mass-media. The research tries to find out if there is any correlation between Jobs' death and the Apple brand. On October 5, 2011, the day Steve Jobs passed away, seven of the twenty hottest topics on the Internet that day were related to the Apple founder. The most searched topic on Internet on October 5th, 2011, was, nonetheless, the „Cupertino Shooting”, where an employee opened fire and killed three coworkers, thus also a tragedy. But then, the second hottest topic was „Abdulfattah John Jandali”, Steve Jobs' biological father. His name was so fiercely searched on the Internet because people didn't ever before think about Steve Jobs' family. They were only interested in Steve Jobs and his business, and, suddenly, after his death, while searching for information in order to find out more about Steve Jobs, people realized that he also had a father, about whom almost nobody ever knew anything before, simply because the father didn't stir interest. Now, the existence of the father was like a discovery to many people. They were so shocked about their discovery that they wanted to find out even more, and thus began searching more intense for information about Abdulfattah John Jandali. The third most searched topic on the web was ,pancreatic cancer", the disease that caused the death of the Apple founder, and then, only on the fourth position, was Steve Jobs' name, with people wanting to find out about the person, not about his family or disease. Fifth most searched topic was then „Apple”, the company. The Top 20 included other three Steve Jobs related topics:

-Mona Simpson (11th rank): Steve Jobs' biological sister;

-iSad (14th rank): a pun between „iPad” (Apple's music player and one of the companies most popular products) and the word ,sad", having the goal to show how Apple fans and not only felt about Steve Jobs' death;

-Bill Gates (18th rank): this time people were not interested in the Microsoft founders' personality, but in his reaction to Steve Jobs' death.

Then, also in the Top 20, other three topics were related to tragedies:

-Charles Napier (6th rank): famous American actor, starring in „The Silence of The Lambs”, and who passed away the same day Steve Jobs did;

-Lisa Irwin (15th rank): a missing Missouri baby;

-Shareef Allman (20th rank): the man who opened fire in Cupertino and killed three coworkers, and who was eventually shot dead by Police.
Out of the top twenty searches on Internet on October 5th, 2011, eleven (55\%) were related to tragedies. As earlier seen, „Apple" was the fifth most searched topic on October 5th, 2011. An explanation is that tragedy has immediate effect to brand connection, as there isn't any rational thinking whether to accept the brand or not. People connect directly to the brand because emotions dictate them to do so. Tragedy touches people, making them more sensitive. Feelings lead to emotions, and emotions connect people from all walks of life to the brand which is affected. People reacted emotionally to Steve Jobs' death. Then, they began talking of it. Not only face-to-face. Their dialogues about Steve Jobs and Apple were amplified by e-mails, text messages and social media tools, which lead to a higher reach. Once something about Apple Inc. was displayed in social media, it took only seconds until it got all over the world. It was the consumers, shocked and touched by emotion, who now did the buzz and the marketing for Apple. Meanwhile, as a company of its dimensions should have done, Apple kept discretion. Consumers acted as ambassadors of the brands. They were not only simple consumers, but what Roberts (2004) calls inspirational consumers: people who love a brand so much that they want to communicate their emotions related to that brand to other people as well.

Tragico-emotional brand connection was also reflected by other gestures that people, toched by Steve Jobs' death, did:

- in front of Apple stores world-wide people have laid, next to bunches of flowers, bitten apples, reproducing the company's logo;

- iSad: a pun expressing people's feelings;

- a logo of Apple was created in which the bite in the apple has not a linear shape, as usual, but is actually a carving of Steve Jobs' face in profile (HotNews, 2011).

As a matter of fact, Steve Jobs' death had such an impact that it rebrought the bitten apple, Apple's logo, into attention. On October 6th, if searching the word ,apple” on Google, a internet user could find out that all the images displayed by the search engine on its first page were related to the Apple company, no single one having anything to do with the fruit. Sixteen of the twenty two were variations of the Apple logo, the other six being images of Apple products: three pictures of the iPhone, two of the MacBook and one of the Apple Tablet. The company became more popular than the fruit. It is what marketing calls ,generic trademarks": when a name becomes the generic description of a product or a company, and stops being only an indicator which has the goal to help the costumer link the name to a particular company. Next to Apple, generic trademarks include the likes of Xerox, Thermos, or Heroine. With each innovation brought to the market, Apple began being more than only Jobs' property: it was also becoming its consumers' property. With each innovation, Apple and Jobs melted together. When Jobs passed away, consumers felt like they lost a part of their property. They turned to Apple to seek alienation. Apple was the friend they were looking for in times of despair. Steve Jobs and Apple evolved to synonymous brands. Each mentioning of Steve Jobs was linking to Apple. Thus, the notoriety of the company increased even further when 
personalities such as Barack Obama, Bill Gates, Arnold Schwarzeneger, Larry Page, Spike Lee, Norman Foster and many others publicly brought their tribute to Jobs. The growth of Apple's popularity after Steve Jobs' death was also driven by Facebook. According to the statistics provided by the Internet traffic monitoring site www.alexa.com, Facebook was the third most searched query for Apple's official website, acquireing $1,66 \%$ of the days' Internet searches (Alexa.com, 2011). Query is a phrase or a word that drives traffic to a site. This means that $1,66 \%$ percent of the search trafic on the Internet was directed to finding the official Facebook profile of Apple. These 1,66\% were redirected to the link on the official Apple website that gave access to the Facebook profile. Moreover, on October 6th, $6,75 \%$ of all Apple official website visits were preceded by Facebook visits, and $8,94 \%$ were followed by a Facebook visit. Many of the website visits were driven by accessing the links shared by worldwide consumers on Facebook, and also that, after visiting the company's webpage, many users wanted to connect on Facebook, mostly for leaving messages in the memory of Steve Jobs. More than 100 profiles labelled „RIP Steve Jobs" were created on Facebook within two days of his death (Phillipine Daily Inquirer, 2011), while millions of users changed their profile pictures to a real apple or the Apple logo, and more than 3000 videos were uploaded onto YouTube (New York Times, 2011). The estimated percentage of global pageviews on www.apple.com rose by 12,2 percent in the day of Steve Jobs' death, as compared to the previous day, the estimated percentage of global Internet users who visited the website rose by 18 percent, and the visits that consisted of a single pageview rose by 8 percent (Alexa.com, 2011). Shortly after Steve Jobs' death, $20 \%$ of the messages sent via Twitter contained the word „Steve Jobs" (Mediafax, 2011). One day after his death, 5.9 percent of all Twitter messages contained the word ,apple" (Trendistic, 2011). According to Roberts (2004), people connect with brands becuase brands make them feel better, relax and enjoy. Through his leadership, Steve Jobs reached the feelings of the Apple fans. Jobs' vision of a mobile phone without buttons materialized in the iPhone, the first touchscreen phone in the world, a gadget that reached the emotions of people through texture and sight. His vision of buying music from the Internet and not anymore on CD's, materialized in the iPod, a gadget that reached people through sound. Jobs made consumers love Apple products because of their usefulnes and of the added entertainment-value these products brought to their lives. Once Jobs died, many people felt like they have lost a close friend, and much of their attention turned not only to Jobs, but to Apple as well. It was only now that many people realized how much innovation Jobs brought into the products he created. People began thinking of the iPod or the iPhone as some sort of particular products which revolutionized the world. Although these products existed on the market for several years now, consumers paid more attention to them after Jobs' death. And when consumers thought about the products, they also thought about the company that built them. As a result, Apple's notoriety grew. This effect did not occur only on indivdual level, but also on mass level. Televisions and newspapers started reporting more and more about Apple, bringing the company in the public attention.

\section{NECROMARKETING}

Necromarketing happens suddenly. It is not expected and then, out of nowhere, it happens. Or, even if a death is expected, it is not wanted. Steve Jobs' death was expected, as his health worsened continuously, and he even resigned as Apple's CEO in August 2011. But nobody wanted to think about his death. It was only after his death that news were produced and books were published. The boundary between ethic behaviour and reality is thin. When a tragedy occurs people suddenly feel attached to a brand they may have not even paid attention to in the past. Being overwhelmed by the emotion released of the breaking news announcing the death, human behavior becomes irrational and it connects to the brand only on emotional basis. Emotions are a strong connector (Duffy, 2003; Travis, 2000), as they may make the consumer forget possible imperfections a brand may have. As a consequence, the notoriety of the brand raises. This is reality and it cannot be hidden, it simply occurs. Ethic behaviour would mean not trying to capitalize on the tragedy by launching planned, directed marketing campaigns, aiming at attracting new consumers and improving brand notoriety, by using the tragedy as a driver. Reality just does it. Necromarketing is the type of marketing that does not need any marketers in order to work: it simply attracts the attention of masses and makes them exchange information about the brand without even being exposed to advertising or public relations. It is the masses that automatically market the brand by talking about it. In an overcrowded media environment, where there is so much noize, so many TV channels, radio stations, news websites and newspapers, tragedy suddenly attracts attention and makes the headlines, because of the shock that comes with it. No exquisite marketing decisions are even needed.

\section{CONCLUSIONS}

The figures presented in the paper show that there is a correlation between tragedy and notoriety, as people pay more attention when receiving shocking news. After Jobs' death, the Apple brand was used in various ways in order to commemorate its founder, while social media interactions boosted. A limitation is that it does not provide any correlation indicators, like the Pearson correlation coefficient. Therefore, further research could concentrate on testing the statistical or econometrical correlation between the two variables, death and brand, by using specialized software, like for example SPSS. Another research could investigate if and how above the line and below the line marketing respond to tragedies.

\section{REFERENCES}

Duffy, N. (2003). Passion Brandind. Harnessing the power of emotions to build strong brands, John Wiley \& Sons Ltd., Chichester, West Sussex, ISBN 0-470-85052-3.

Roberts, K. (2004). Lovemarks, powerhouse Books, New York, ISBN 1-57687-204-1.

Travis, D. (2000). Emotional Branding, Prima Publishing, Roseville, ISBN 0-7615-2911-X.

*** (2011) http://www.alexa.com/siteinfo/apple.com\# Alexa.com, Accessed on 2011-10-07

*** (2011) http://www.hotnews.ro/stiri-international10346225-omagiul-adus-lui-steve-jobs-student-din-hongkong.htm - HotNews: „Omagiul adus lui Steve Jobs de un student din Hong Kong, Accessed on 2011-10-07

*** (2011) http://www.mediafax.ro/cultura-media/reactii-peretelele-de-socializare-dupa-moartea-lui-steve-jobs8842364/ - Mediafax: „Reacţii pe rețelele de socializare, după moartea lui Steve Jobs": Accessed on 2011-10-07

***(2011) http://technology.inquirer.net/5123/world\%E2\%80\% 99s-netizens-mourn-death-of-\%E2\%80\%98visionary-andcreative-genius\%E2\%80\%99/ - Phillipine Daily Inquirer: „World's netizens mourn death of , visionary and creative genius"”, Accessed on 2011-10-07

*** (2011) http://mediadecoder.blogs.nytimes.com/2011/10/06 /tributes-to-steve-jobs-flood-social-media-platforms/ „Tributes to Steve Jobs Flood Social Media Platforms”, The New York Times, Accessed on 2011-10-07

*** (2011) Trendistic. http://trendistic.indextank.com/apple, Accessed on 2011-10-07 